\title{
Distinguishing implicit and explicit learning
}

\author{
MICHAEL A. STADLER \\ University of Missouri, Columbia, Missouri
}

\begin{abstract}
I agree with Dienes and Berry's (1997) and Neal and Hesketh's (1997) call for investigations of the qualitative differences between implicit and explicit learning and note that such investigations must be guided by a workable definition of what is implicit and by theories that predict what the qualitative differences might be. Following Schacter, Bowers, and Booker's (1989) retrieval intentionality criterion, I propose using an encoding intentionality criterion to distinguish implicit from explicit learning; we can reasonably infer that implicit learning has occurred when a variable known to influence explicit learning has no effect in a comparable implicit learning condition. I then suggest that implicit learning depends on noncognitive, nonhierarchical associations, whereas explicit learning depends on cognitive, hierarchical associations, and briefly describe an experiment that confirms a qualitative difference between implicit and explicit learning predicted by this hypothesis.
\end{abstract}

Thorndike (1935) stated,

A person may increase the probability that certain situations will evoke certain responses without knowing at the time that he is doing so or afterward that he has done so. This is evidenced both by experimental records and by facts of ordinary life. No competent psychologist would now dispute it. There is no direct consciousness of learning paralleling the fact of learning and revealing it to the learner. (p. 62)

Despite the vehemence of Thorndike's pronouncement, many psychologists have disputed claims that learning can occur unconsciously (e.g., Brewer, 1974; Dulany, 1961; Dulany, Carlson, \& Dewey, 1984, 1985; Eriksen, 1960; Shanks \& St. John, 1994). The lead articles in this symposium differ somewhat in their positions on this issue. Neal and Hesketh (1997) tend to agree with the disputers that there is no convincing evidence for implicit learning as it is currently conceived, whereas Dienes and Berry (1997) suggest that positive evidence for implicit learning will be obtained when an appropriate definition of awareness, a subjective one, is adopted. Despite this disagreement, both papers emphasize, as have others (e.g., Merikle, 1994; Stadler \& Frensch, 1994), the need for investigating qualitative differences between implicit and explicit learning. Such investigations will depend on two things: a workable definition of the distinction between implicit and explicit, and some theoretical ideas about what the qualitative differences might be.

The author is grateful to Beryl Hesketh, Andrew Neal, Roddy Roediger, and two anonymous reviewers for helpful comments on a previous draft of this paper. Correspondence should be addressed to the author at the Department of Psychology, University of Missouri, 210 McAlester Hall, Columbia, MO 65211 (e-mail: psymike@showme. missouri.edu).

\section{DEFINING IMPLICIT AND EXPLICIT LEARNING}

Stanovich (1992) contrasts operationism and essentialism, two approaches to the definition of theoretical constructs. Operationism, of course, is the logical positivist practice of defining theoretical constructs by their relation to observable variables. The original definitions of what is implicit, in both the implicit learning and the implicit memory literatures, provided quite clear direction for operational definition of the term. Reber (1967) wrote that implicit learning is a process in which "information is abstracted out of the environment ... without recourse to explicit strategies for responding or systems for recoding the stimuli" (p. 863). Similarly, Graf and Schacter (1987) wrote that "[e]xplicit memory is revealed by intentional recollection from a specific previous episode, whereas implicit memory is revealed when performance on a task is facilitated without deliberate recollection from a specific learning episode" (p. 501). In the context of Neal and Hesketh's call for a shift in emphasis from awareness to intention, it is interesting that the original definitions of implicit processing focused largely on just that.

Operationism contrasts with essentialism, which is the attempt to define a theoretical construct by its true essence, in some ultimate sense. The debate about whether implicit learning is truly unconscious sometimes seems to run along essentialist lines. Indeed, the terms conscious and unconscious seem made to order for an essentialist debate. Were we to focus more on developing an operational definition of what is implicit, we would simply look for a definition that meaningfully and reliably helps us distinguish implicit from explicit learning. Of course, if no such definition can be found, then the distinction between implicit and explicit learning will not be worth making. Several operational definitions have been proposed, including those based on free verbal reports, the 
objective or subjective thresholds, and manipulations of intention.

\section{Free Report}

Some of the subjects in my serial reaction time (RT) experiments (e.g., Stadler, 1995) finish the task, emerge from their cubicles with a pleased expression and announce that they have figured out the experiment, having noticed the "secret pattern." Other subjects, when informed that there was a pattern, seem somewhat embarrassed and reluctantly admit that they did not notice it. Surprisingly, when given a more direct test of their explicit knowledge, these two types of subject often perform about the same. Some of the confident subjects seem to have "discovered" regularities in the task that were not actually there; some of the less confident ones realize that they knew more than they at first thought. Because of this and other problems, most researchers, including myself, would agree with Dienes and Berry (1997) that free report "is a relatively insensitive and incomplete measure" and so have begun to rely more on various forms of objective or subjective tests.

\section{Objective Tests}

Objective tests are those in which subjects are asked to make forced-choice judgments; if performance exceeds what would be expected by chance, subjects are judged to be aware of the to-be-learned material. As reviewed by Neal and Hesketh (1997), two assumptions about explicit tests are the exhaustiveness assumption, which holds that a given direct measure is sensitive to all relevant conscious knowledge, and the exclusiveness assumption, which holds that a given direct measure is insensitive to any unconscious knowledge (Reingold \& Merikle, 1988). Concerned with the exhaustiveness of explicit measures, critics of the implicit learning construct have generally favored objective tests of awareness. This preference seems to be based on a definition that requires that demonstrations of implicit learning must prove that subjects have absolutely no awareness of what has been learned. This may be reasonable, given the frequency with which claims of unconscious learning (i.e., learning without awareness) have been made. On the other hand, concerns about the exclusiveness of objective tests are also warranted. In the perhaps likely event that explicit tests are contaminated by implicit knowledge (cf. Roediger \& McDermott, 1993), true cases of implicit learning might be missed if we resort only to objective tests.

The tension between these two approaches is illustrated by the typical string classification test of implicit knowledge used in artificial grammar learning experiments. Subjects are instructed to decide whether or not a test string follows the same rules as the strings shown in the training phase (e.g., Reber, 1976). By an objective definition, which holds that any discriminative responding at a rate better than chance indicates conscious awareness (Holender, 1986; Reingold \& Merikle, 1988), this is a direct test. Of course, Reber and many others have never regarded these results this way, which shows how difficult it is to arrive at a mutually agreeable a priori definition of awareness.

Still, objective tests may not always be contaminated, and even when they are, the contamination may not be severe. Moreover, objective tests are the most conservative and the most likely to convince critics of the implicit learning concept. Thus, a demonstration of learning in which subjects perform at chance on an objective measure of explicit knowledge should be quite convincing. Indeed, after a thorough analysis of the exhaustiveness and exclusiveness assumptions and the problems associated with them, Reingold and Merikle (1988, p. 566) showed that, with the simple assumption that direct measures are at least as sensitive to conscious knowledge as indirect measures, "unconscious perception is demonstrated whenever an indirect measure shows greater absolute sensitivity than does a comparable direct measure to a particular stimulus dimension." Neal and Hesketh (1997) recognized the problems with the exhaustiveness and exclusiveness assumptions outlined by Reingold and Merikle, but they seem to have missed or forgotten about the potential solution to those problems.

A recent experiment from my laboratory illustrates the possibilities in the approach advocated by Reingold and Merikle (1988), although it admittedly did not meet all of their criteria for comparable direct and indirect measures - something they noted would be difficult to accomplish in a single experiment. Subjects were trained on a serial RT task in which six locations were aligned horizontally across the screen. As usual, the subjects pressed a key corresponding to each location whenever an asterisk appeared there. For several blocks of training, the asterisk followed a 12-trial second-order conditional (see Reed \& Johnson, 1994) repeating sequence. In the next phase of the experiment, after being informed about the presence of the repeating sequence, subjects responded to several short runs of three trials, half of which were from the repeating sequence and half of which were new. The implicit measure of learning was the difference between their RTs for the old and new runs (looking only at the second and third trials of each run). Then, after each run of three trials, subjects were asked to make a recognition judgment indicating whether or not that run of three trials was from the repeating pattern. This recognition test meets Shanks and St. John's (1994) criteria for acceptable direct measures because the indirect and direct tests depended on identical stimuli (meeting the information criterion) and the two testing contexts were identical (meeting the sensitivity criterion).

The key result is that subjects who performed no better than would be expected by chance on the recognition test still showed a significant advantage for old over new runs on the RT measure. Although, as noted above, it must be granted that the recognition and RT measures are not directly comparable, by Reingold and Merikle's (1988) 
reasoning, this qualifies as a demonstration of unconscious learning because the indirect measure was more sensitive than the direct measure. Thus, if it is possible to investigate implicit learning with an objective measure of explicit knowledge, then we should do so, because such evidence is most likely to convince the disputers, who tend to specify objective criteria (e.g., Eriksen, 1960; Holender, 1986; Shanks \& St. John, 1994). Both Dienes and Berry (1997) and Neal and Hesketh (1997) may have given up too soon on this approach.

\section{Subjective Tests}

A subjective measure asks subjects to assess how well they did on an objective measure; if they believe they were only guessing, they are judged to be unaware of the to-be-learned material. In practice, because it is relatively easy to employ one if the other is being used, I would suggest the use of both an objective and a subjective test. Given the positive results with an objective test just described, I currently favor the use of that measure. However, if I were to give in to the essentialist impulse and try to pick a definition of consciousness based on what seemed most reasonable, I would probably choose a subjective test. Ultimately, I think Dienes and Berry (1997), like Cheesman and Merikle (1986), were correct in judging this to be the most appropriate definition. If subjects believe their performance on an objective measure to have been based on nothing more than guessing, there is no face validity in saying that their knowledge is conscious if they happen to perform better than chance on an objective measure. Rather, it is likely that the exclusiveness assumption has been violated. What should matter in distinguishing implicit from explicit learning is what subjects do with knowledge if and when they become aware they have it. Returning to the original operational definitions quoted above, we should be more concerned with the distinction between intentional and unintentional learning. Thus, even if subjects are able to perform better than chance on an explicit measure, if they believe that they do not possess the knowledge required to do this and say they are only guessing, it is unlikely that they will employ any intentional learning strategies. Indeed some subjects (e.g., perhaps those low in need for cognition; Caccioppo \& Petty, 1982) may not use intentional learning strategies even if they happen to become aware of the to-be-learned material. Learning in these cases should still be distinguished, if possible, from explicit strategy-driven learning.

\section{Manipulation of Intentions: \\ An Encoding Intentionality Criterion}

The implicit memory literature has probably done a better job of sticking with the original operational definition of what is implicit than has the implicit learning literature. In the former, it is typical for researchers to directly compare implicit retrieval conditions with explicit retrieval conditions. In the latter, it has been rela- tively uncommon for investigators to compare implicit learning conditions with explicit learning conditions.

Schacter, Bowers, and Booker (1989) introduced the retrieval intentionality criterion into the implicit memory literature (Cheesman \& Merikle, 1986, applied similar logic to the problem of subliminal perception). The basic idea is that if direct and indirect tests differ only in terms of the retrieval instructions, then when a variable that influences a direct test in one manner has a contrasting effect on an indirect memory test, it can be concluded that subjects did not engage in intentional retrieval strategies on the implicit test (or the effects of that variable would have been similar on both tests). For example, on the basis of findings in which strong levels of processing effects were found in explicit testing conditions but not in directly comparable (i.e., differing only in instructions) implicit testing conditions, Roediger, Weldon, Stadler, and Riegler (1992) argued that word fragment and word stem completion tests were not contaminated by explicit retrieval processes.

The same logic has great potential for the problem of implicit learning. Consider an experiment in which some pattern or rule is embedded in the stimulus structure of a task. One group of subjects, when told how to perform the task, is also given intentional learning instructions directing them to try to learn the pattern or rule; another group is told only how to perform the task. Otherwise, the two conditions are identical. If a variable influenced performance in the explicit learning condition one way and that in the implicit learning condition another way, then the disputers could not easily claim that performance in the implicit learning condition actually depended on explicitly acquired knowledge (Shanks \& St. John, 1994); if that were so, then the effects of that particular variable would have been expected to be the same in the implicit condition as in the explicit condition. A more plausible explanation would be that learning in the implicit condition proceeded according to one set of principles and that learning in the explicit condition proceeded according to another. Neal and Hesketh (1997) suggest the use of the retrieval intentionality criterion as a converging operation in the study of implicit learning. I would go further and suggest that use of an encoding intentionality criterion, such as that outlined here, may be the most effective way to demonstrate implicit learning. To date, relatively few experiments have used such an approach. Hayes and Broadbent (1988) claimed to have provided one such test, but Green and Shanks (1993) had difficulty replicating it. Below, I will describe another such test.

\section{THEORETICAL CONSIDERATIONS}

Dienes and Berry (1997) listed several properties that might mark implicit learning; Neal and Hesketh (1997) argued for the episodic basis of implicit knowledge. I have some concerns about whether these ideas will help us distinguish implicit from explicit learning. 


\section{Properties of Implicit Learning}

Flexibility. Is implicit learning inflexible, and is explicit flexible? Cohen, Ivry, and Keele (1990) and Stadler (1989) both showed that implicit learning in a serial RT task transfers completely when the effectors used for responding are changed. Considering that classical conditioning might occur implicitly (Shanks \& St. John, 1994, included conditioning in the review of implicit learning), these findings call to mind Wickens's (1938) demonstration that a conditioned finger extension will immediately become a conditioned finger flexion if the subject's hand is simply turned over. Even the most basic learned responses can at times be flexible.

Another problem is the question, How flexible is flexible? Granted, when subjects are transferred from one condition to another - as when they are switched from one letter set to another in an artificial grammar learning experiment (e.g., Reber, 1969)--performance may be somewhat lower than when conditions remain the same (actually, in Reber's experiment, performance in these two conditions was nearly identical). However, the finding that knowledge transfers at all in such a situation seems quite impressive; I am not sure I would want to use such a finding as evidence of inflexibility.

Even if we agree that implicit learning is inflexible, inflexibility is surely not unique to implicit learning. Explicit learning and memory can also be quite inflexible. In the well-known encoding specificity effect (Tulving $\&$ Thomson, 1973), subjects sometimes fail to recognize a word that was studied in the context of a paired associate, but then they can recall the word when the associate is used as a cue (Watkins \& Tulving, 1975). Godden and Baddeley (1980) showed that recall is best if it takes place in the same context as study; divers' memory was better when both study and recall took place on land or underwater than when study occurred in one place and recall in the other. Eich (1989) reviewed similar studies in which context was manipulated internally, rather than externally, by variations in sobriety, drug state, mood state, and even across the personalities of a subject with multiple personality disorder. Although there appear to be limits to some of these effects (Eich, 1995), the general finding is that recall is best when study and test occur in the same state. Finally, demonstrations of transferappropriate processing show that recall depends on the similarity of mental operations carried out at study and test. Bransford, Franks, Morris, and Stein (1979) reviewed evidence showing that cued recall is best when the processing at study (e.g., semantic, phonemic, graphemic) matches the processing encouraged by the cue given at the time of recall. Inflexibility is not exclusively a property of implicit learning.

Focus on items and not rules. According to Dienes and Berry (1997), "implicit learning tends to be associated with observation and memorization conditions, rather than with deliberate hypothesis testing" (p. 5). This factor, it seems to me, covaries almost perfectly with the distinction between unintentional and intentional learning. Almost any task that asks subjects to attend to underlying rules, patterns, or covariations will be an intentional learning task (in effect if not in design). Thus, if we adopt the encoding intentionality criterion, this factor is a characteristic of implicit learning almost by definition and would not be useful as an attribute to be used to identify implicit learning.

The evidence Dienes and Berry (1997) cited in support of this feature of implicit learning was from a few studies showing that implicit learning instructions led to greater learning than did explicit learning instructions. One account of this is that deliberate hypothesis testing about complex patterns of stimuli sometimes leads explicit learning subjects to adopt incorrect hypotheses, which later hurt their performance. Note, however, that after telling subjects to search for rules, it is difficult to "put the genie back in the bottle" so that they can perform the task implicitly. They may well have acquired the same implicit knowledge as the subjects in the implicit learning condition, but then that knowledge was not evident in task performance because of whatever explicit strategies they were using. Given that many theorists regard implicit learning and memory as automatic (e.g., Jacoby, 1991; Lewicki, 1986; Reber, 1993; Stadler, 1995), this seems a quite plausible possibility. Indeed, Jacoby, Woloshyn, and Kelley (1989) demonstrated that intentional processing can interfere with the expression of implicit memory. After studying a list of nonfamous names under single- or dual-task conditions, subjects made fame judgments about another list of names, some famous and some nonfamous, with some of the nonfamous names being repeated from the first phase of the experiment. In the single-task condition, subjects were apparently able to make use of their memory for the names seen during the first phase of the experiment, thus using that as a cue to call a name "nonfamous." In the dual-task condition, subjects were unable to do this, so the influence of implicit memory for the studied nonfamous names came into play and led subjects to call many of the nonfamous names "famous." Therefore, implicit learning may occur under explicit learning conditions; it just may be more difficult to see.

Robustness. The evidence that implicit learning is more robust than explicit when there is damage to the hippocampus is quite compelling (Knowlton, Ramus, \& Squire, 1992; Knowlton \& Squire, 1994; Musen \& Squire, 1993). However, evidence for robustness in other disorders can be interpreted in different ways. Instead of regarding the evidence of impaired implicit learning in Huntington's disease as being due to "widespread general neural degradation" (Dienes \& Berry, 1997, p. 18), it might be regarded as evidence for the role of the striatum in some kinds of implicit learning (Petri \& Mishkin, 1994). Knowlton, Mangels, and Squire (1996) recently reported a double dissociation in which amnesic patients were impaired on an explicit, but not implicit, task, and 
patients with Parkinson's disease showed the reverse pattern. They too interpreted their findings as evidence for the role of the striatum in at least one form of implicit learning. Finally, as Dienes and Berry (1997) acknowledge, implicit learning may be robust to the imposition of some secondary tasks, but not others (Stadler, 1995). Like the notion of flexibility, robustness may be too broad a concept to be useful in making a sharp distinction between implicit and explicit learning.

\section{Abstract Versus Episodic Representations}

Deciding between abstract and episodic representational systems is a difficult issue, and one on which a great deal of effort has been expended. Neal and Hesketh (1997) marshal a great deal of evidence to support the episodic position, but there are several lines of defense supporting the other side. Many types of episodic representation effectively produce abstraction, and many types of abstract representation preserve episodic information (Barsalou, 1990). For example, if only a subset of the features of an episode are stored (e.g., the first letter of a string from an artificial grammar), what is left would in effect be a general rule, albeit an imperfect one (Goldstone \& Kruschke, 1994; Mathews, 1990). Ultimately, it may not even be possible empirically to distinguish, in a broad sense, abstract from episodic representations, although detailed models might be compared (Barsalou, 1990). As Barsalou showed, the various kinds of evidence that are offered as support for episodic representation, including those reviewed by Neal and Hesketh, can be explained relatively easily by various kinds of models that assume abstract representations. Neal and Hesketh say several times that episodic knowledge influences performance on implicit learning tasks. This does not necessarily imply that the underlying representation is episodic.

Barsalou (1990) also emphasized the importance of considering the processes that operate on whatever representation is assumed. It might be fruitful to consider how intentional and unintentional processes differentially encode episodic information. It probably will not be fruitful to try to distinguish episodic from abstract representations in a broad sense.

\section{SOME EVIDENCE OF QUALITATIVE DIFFERENCES BETWEEN IMPLICIT AND EXPLICIT LEARNING}

I have recently begun some work that is motivated by a theory that posits two kinds of associative representation, which I will sketch briefly here. Capitalizing on a distinction made by Wickelgren (1979) and adding a few additional assumptions about processing, the idea is that implicit, unintentional learning is based on horizontal associations, whereas explicit, intentional learning consists of the formation of vertical associations. Horizontal associations are the result of the contiguous activation of two nodes in memory, such as, for example, when one event in a serial RT task is followed by another.
These associations are assumed to be noncognitive, making them a simple, or "dumb," representation, as implicit or nonconscious representations have been hypothesized to be (Greenwald, 1992). Such associations can be quite powerful in serial learning, however, if one assumes the possibility of weaker, remote associations between nearby noncontiguous events (e.g., between the letter $A$ and the letter $C$ in the alphabet; Ebbinghaus, 1885/1964; Slamecka, 1985).

Vertical associations are the result of chunking (Miller, 1956) and form a hierarchical representation in which one node in memory comes to stand for subordinate nodes, such as when we use a mnemonic (e.g., homes) to remember the names of the Great Lakes, or when we code a sequence of events in a serial RT task as a run (ABC) or a trill (ABA; see Restle, 1970). They are cognitive, the result of intentional processing (not necessarily intentional recoding) of the elements of the association, and so presumably depend on factors such as attention, effort, and so on. Note that this distinction is similar to one made by Keele and his colleagues (Cohen et al., 1990; Curran \& Keele, 1993), except that, in the present theory, hierarchical associations occur only under explicit learning conditions. In the theory they proposed, there were two implicit learning mechanisms, one attentional and one not, with the attentional one able to form hierarchical associations and the nonattentional one not. In my view, there is one implicit learning mechanism, and it is distinctly nonhierarchical.

One prediction from this model is that manipulations of the response-stimulus interval (RSI) in the serial RT task should have qualitatively different effects on implicit (unintentional) and explicit (intentional) learning. Implicit learning, if it depends on horizontal associations, should be greater when the sequence of events is more contiguous - that is, when the RSI is short (see Frensch \& Miner, 1994). Explicit learning, if it depends on vertical associations, should be greater when the RSI is longer, thus affording the subject more opportunity for recoding the sequence. Manipulation of the RSI should thus have opposite effects on implicit and explicit learning. In my laboratory, we recently completed a pilot experiment that was designed to test this prediction and obtained positive results. Further experiments are currently under way.

This illustration is used here not so much to promote the theory as to demonstrate the effectiveness of an approach that compares intentional and unintentional learning and seeks to find qualitative differences between them. Although they disagree on other points, Dienes and Berry (1997) and Neal and Hesketh (1997) agree that this approach should be most effective, and I think they are right. Perhaps someday more psychologists will think that Thorndike (1935) was right, too.

\section{REFERENCES}

BARSALOU, L. W. (1990). On the indistinguishability of exemplar memory and abstraction in category representation. In T. K. Srull \& R. S. 
Wyer, Jr. (Eds.), Advances in social cognition, Vol. III: Content and process specificity in the effects of prior experiences (pp. 61-88). Hillsdale, NJ: Erlbaum.

Bransford, J. D., Franks, J. J., Morris, C. D., \& Stein, B. S. (1979). Some general constraints on learning and memory research. In L. S. Cermak \& F. I. M. Craik (Eds.), Levels of processing in human memory (pp. 331-354). Hillsdale, NJ: Erlbaum.

BREWER, W. F. (1974). There is no convincing evidence for operant or classical conditioning in adult humans. In W. B. Weimer \& D. S. Palermo (Eds.), Cognition and the symbolic processes (pp. 1-61). Hillsdale, NJ: Erlbaum.

CACCIOPPO, J. T., \& PETTY, R. E. (1982). The need for cognition. Journal of Personality \& Social Psychology, 42, 116-131.

Cheesman, J., \& Merikle, P. M. (1986). Distinguishing conscious from unconscious perceptual processes. Canadian Journal of Psychology, 40, 343-367.

Cohen, A., Ivry, R. I., \& KeEle, S. W. (1990). Attention and structure in sequence learning. Journal of Experimental Psychology: Learning, Memory, \& Cognition, 16, 17-30.

Curran, T., \& Keele, S. W. (1993). Attentional and nonattentional forms of sequence learning. Journal of Experimental Psychology: Learning, Memory, \& Cognition, 19, 189-202.

DienES, Z., \& Berry, D. (1997). Implicit learning: Below the subjective threshold. Psychonomic Bulletin \& Review, 4, 3-23.

DULANY, D. E. (1961). Hypotheses and habits in verbal "operant conditioning." Journal of Abnormal \& Social Psychology, 63, 251-263

Dulany, D. E., Carlson, R. A., \& Dewey, G. I. (1984). A case of syntactic learning and judgment: How conscious and how abstract? Journal of Experimental Psychology: General, 113, 541-555.

Dulany, D. E., Carlson, R. A., \& Dewey, G. I. (1985). On consciousness in syntactic learning and judgment: A reply to Reber, Allen, and Regan. Journal of Experimental Psychology: General, 114, 25-32.

EbBinghaus, H. (1964). Memory: A contribution to experimental psy$\operatorname{chology}($ H. A. Ruger \& C. E. Bussenius, Trans.). New York: Dover. (Original work published 1885 )

Eich, E. (1989). Theoretical issues in state dependent memory. In H. L. Roediger III \& F. I. M. Craik (Eds.), Varieties of memory and consciousness: Essays in honour of Endel Tulving (pp. 331-354). Hillsdale, NJ: Erlbaum.

EICH, E. (1995). Searching for mood dependent memory. Psychological Science, 6, 67-75.

ERIKSEN, C. W. (1960). Discrimination and learning without awareness: A methodological survey and evaluation. Psychological Review, 67, 279-300.

FrenSCH, P. A., \& Miner, C. S. (1994). Effects of presentation rate and individual differences in short-term memory capacity on an indirect measure of serial learning. Memory \& Cognition, 22, 95-110.

Godden, D., \& BADDELEY, A. D. (1980). When does context influence recognition memory? British Journal of Psychology, 66, 325-331.

Goldstone, R. L., \& KRuschKe, J. K. (1994). Are rules and instances subserved by separate systems? Behavioral \& Brain Sciences, 17, 405.

Graf, P., \& SCHACTER, D. L. (1987). Selective effects of interference on implicit and explicit memory for new associations. Journal of $E x$ perimental Psychology: Learning, Memory, \& Cognition, 11, 45-53.

Green, R. E. A., \& Shanks, D. R. (1993). On the existence of independent explicit and implicit learning systems: An examination of some evidence. Memory \& Cognition, 21, 304-317.

Greenwald, A. G. (1992). New look 3: Unconscious cognition reclaimed. American Psychologist, 47, 766-779.

HAYES, N. A., \& BroadBent, D. E. (1988). Two modes of learning for interactive tasks. Cognition, 28, 249-276.

HOLENDER, D. (1986). Semantic activation without conscious identification in dichotic listening, parafoveal vision, and visual masking: $\mathrm{A}$ survey and appraisal. Behavioral \& Brain Sciences, 9, 1-23.

JACOBY, L. L. (1991). A process dissociation framework: Separating automatic from intentional uses of memory. Journal of Memory \& Language, 30, 513-541.

JaCoBY, L. L., Woloshyn, V., \& Kelley, C. (1989). Becoming famous without being recognized: Unconscious influence of memory pro- duced by dividing attention. Journal of Experimental Psychology: General, 118, 115-125.

Knowlton, B. J., Mangels, J. A., \& Squire, L. R. (1996, September 6). A neostriatal habit learning system in humans. Science, 273, 1399-1402.

Knowlton, B. J., Ramus. S. J., \& SQuire, L. R. (1992). Intact artificial grammar learning in amnesia: Dissociation of classification learning and explicit memory for specific instances. Psychological Science, 3, 172-179.

Knowlton, B. J., \& SQuire, L. R. (1994). The information acquired during artificial grammar learning. Journal of Experimental Psychology: Learning, Memory, \& Cognition, 20, 79-91.

LEWICKI, P. (1986). Nonconscious social information processing. New York: Academic Press.

Mathews, R. C. (1990). Abstractness of implicit grammar knowledge: Comments on Perruchet and Pacteau's analysis of synthetic grammar learning. Journal of Experimental Psychology: General, 119, 412-416.

MERIKLE, P. M. (1994). On the futility of attempting to demonstrate null awareness. Behavioral \& Brain Sciences, 17, 412.

Miller, G. A. (1956). The magical number seven, plus or minus two: Some limits on our capacity for processing information. Psychological Review, 63, 81-97

MUSEN, G., \& SQUIRE, L. R. (1993). Implicit learning of color-word associations using a Stroop paradigm. Journal of Experimental Psychology: Learning, Memory, \& Cognition, 19, 789-798.

NeAl, A., \& Hesketh, B. (1997). Episodic knowledge and implicit learning. Psychonomic Bulletin \& Review, 4, 24-37.

PetRI, H. L., \& Mishkin, M. (1994, January-February). Behaviorism, cognitivism, and the neuropsychology of memory. American Scientist, 82, 30-37.

REBER, A. S. (1967). Implicit learning of artificial grammars. Journal of Verbal Learning \& Verbal Behavior, 6, 855-863.

REBER, A. S. (1969). Transfer of syntactic structure in synthetic languages. Journal of Experimental Psychology, 81, 115-119.

REBER, A. S. (1976). Implicit learning of synthetic languages: The role of instructional set. Journal of Experimental Psychology: Human Learning \& Memory, 2, 88-94.

ReBer, A. S. (1993). Implicit learning and tacit knowledge: An essay on the cognitive unconscious. New York: Oxford University Press.

REED, J., \& JOHNSON, P. (1994). Assessing implicit learning with indirect tests: Determining what is learned about sequence structure. Journal of Experimental Psychology: Learning, Memory. \& Cognition, 20, 585-594.

Reingold, E. M., \& MerikLE, P. M. (1988). Using direct and indirect measures to study perception without awareness. Perception \& Psychophysics, 44, 563-575.

RESTLE, F. (1970). Theory of serial pattern learning: Structural trees. Psychological Review, 77, 481-495.

RoEDiger, H. L., III, \& MCDermotT, K. (1993). Implicit memory in normal human subjects. In F. Boller \& J. Grafman (Eds.), Handbook of neuropsychology (Vol. 8, pp. 63-130). Amsterdam: Elsevier.

Roediger, H. L., III, Weldon, M. S., Stadler, M. A., \& Riegler, G. L. (1992). Direct comparison of two implicit memory tests: Word fragment and word stem completion. Journal of Experimental Psychology: Learning, Memory, \& Cognition, 18, 1251-1269.

SCHACTER, D. L., BOWERS, J. S., \& BOOKER, J. (1989). Intention, awareness and implicit memory: The retrieval intentionality criterion. In S. Lewandowsky, J. Dunn, \& K. Kirsner (Eds.), Implicit memory: Theoretical issues (pp. 47-65). Hillsdale, NJ: Erlbaum.

Shanks, D. R., \& ST. JOHN, M. F. (1994). Characteristics of dissociable human learning systems. Behavioral \& Brain Sciences, 17, 367-447.

SLAMECKA, N. J. (1985). Ebbinghaus: Some associations. Journal of Experimental Psychology: Learning, Memory, \& Cognition, 11, 414-435.

STAdLER, M. A. (1989). On learning complex procedural knowledge. Journal of Experimental Psychology: Learning, Memory, \& Cognition, 15, 1061-1069.

STADLER, M. A. (1995). Role of attention in implicit learning. Journal of Experimental Psychology: Learning, Memory, \& Cognition, 21, 674-685. 
Stadler, M. A., \& Frensch, P. A. (1994). Whither learning, whither memory? Behavioral \& Brain Sciences, 17, 423-424

STANOVICH, K. E. (1992). How to think straight about psychology (3rd ed.). New York: HarperCollins.

THORNDIKE, E. L. (1935). The psychology of wants, interests, and attitudes. New York: Appleton-Century.

Tulving, E., \& THomson, D. M. (1973). Encoding specificity and retrieval processes in episodic memory. Psychological Review, 80, 352-373.

WATKINS, M. J., \& TulVING, E. (1975). Episodic memory: When recognition fails. Journal of Experimental Psychology: General, 104, 5-29.
WiCKELgREN, W. A. (1979). Chunking and consolidation: A theoretical synthesis of semantic networks, configuring, $S-R$ versus cognitive learning, normal forgetting, the amnesic syndrome, and the hippocampal arousal system. Psychological Review, 86, 44-60.

WiCKENS, D. D. (1938). The transference of conditioned extinction from one muscle group to the antagonistic muscle group. Journal of Experimental Psychology, 22, 101-123.

(Manuscript received September 13, 1996; revision accepted for publication October $1,1996$. 